\title{
Issues surrounding car center stack designs in Malaysia: an exploratory study
}

\begin{abstract}
Car center stack designs have evolved rapidly throughout the years. Manufacturers are working hard in keeping up with the current trends in the automotive market by offering latest technologies embedded into car center stack designs. Consistent with the current trend, Malaysian automotive manufacturers are offering advanced features in car center stacks, which includes touchscreen and navigation systems. Recently car center stacks became the highlight as it became a potential source for driver distraction. An exploratory qualitative study, involving eight regular drivers and two professional drivers were recruited for this exploratory study. A laddering interview technique was applied to reveal chains of attributes, consequences and values. Several prominent attributes related to the value of safety were "Simple Design", "Touchscreen", "Meter Design", and "Multi-Function Steering". Touchscreen systems were perceived differently by professional drivers compared with regular drivers. There is a need for further studies regarding the touchscreen system designs for Malaysian drivers.
\end{abstract}

Keyword: Car center stack; Dashboard; Ergonomics; Interface design; Malaysian; Touchscreen 